\title{
Effects of Transcranial Direct Current Stimulation on the Static Balance Ability of Patients with Back Pain
}

\author{
Seung Keun Oh, Yong Nam Kim \\ Department of Physical Therapy, Nambu University, Gwangju, Korea
}

Purpose: This study examined the effects of transcranial direct current stimulation (tDCS) on the static balance ability of patients with back pain.

Methods: The subjects comprised of 30 males and females in their 20s, who were divided into two groups with and without tDCS. The balance posture ratio score was calculated to determine the changes in balance ability before and after the application of tDCS using balance equipment. A paired t-test was conducted to determine the changes over time, and an independent t-test was performed to determine the changes between the groups. The significance level was set to $\alpha=0.05$.

Results: A significant difference in the changes in the static balance ability of CTDCSG between before and after applying tDCS was observed while the subjects' eyes were open $(p<0.05)$. A comparison between the groups after the experiments revealed significantly increased changes in CTDCSG compared to STDCSE $(p<0.05)$. The changes in static balance ability were not significant when the subjects' eyes were closed $(p>0.05)$.

Conclusion: The application of tDCS positively changed the static balance ability of patients with back pain. The results of this study showed that tDCS could be used as an intervention to increase the static balance ability of patients with back pain in the clinical field. The study results could be used further as foundational data for future studies on tDCS.

Keywords: Transcranial direct current stimulation, Space balance 3D, Balance, Back pain

\section{서 론}

허리 통증은 근골격계 질환 중 보건 치료 우선 순위로 ${ }^{1}$ 거의 모든 사 람들이 평생 동안 허리 통증을 한 번쯤은 경험하게 된다. ${ }^{2}$ 또한 허리 통증의 발병 시기는 10 대부터 발생한다고 보고되고 있으며 ${ }^{3}$ 병리학 적 진단이 없는 허리 부위의 통증으로 정의된다. ${ }^{4}$ 이러한 허리 통증 을 초기에 적절히 중재하지 못하면 만성 허리 통증으로 진행되는 특 징을 보인다.

대표적인 허리 통증의 원인으로는 척추와 골반의 안정성에 영향 을 미치는 몸통 근육의 약화와 부조화 그리고 비정상적인 생체역학 등의 문제들로 발생된다. ${ }^{5}$ 허리 부위에 통증이 발생하면 빠른 움직임 에서 대한 자세 조절에 어려움이 있고 ${ }^{6}$ 자세 조절 결함은 허리 통증 재발에 영향을 미친다. 그러므로 허리 통증 중재를 위해 자세 균형 회복이 중요하다. ${ }^{8}$ 이러한 허리 통증은 일상생활동작에서 삶의 질의 저하를 보이고 재발률과 유병률이 높은 질환에 포함된다. 허리 통증
을 감소시키기 위해 약물치료와 물리치료 중재 등이 제안되어 왔다. ${ }^{10}$ 그러나 정확한 진단과 기준이 없어 치료에 있어 어려움이 있고 중재 기간 역시 오래 걸리는 단점이 있다.

최근 만성 질환의 운동 중재로 단점들을 개선하여 쉽게 적용 가능 하고 효과가 좋은 중재 방법으로 경두개 직류자극(transcranial direct current stimulation, tDCS)이 보고되고 있다. ${ }^{11}$ 경두개 직류자극은 약 한 직류(1-2 mA)를 5 분에서 20분 동안 적용하여 대뇌피질 흥분성에 영향을 주는 방법으로 ${ }^{12}$ 운동영역과 감각영역, 인지영역 등을 조절할 수 있는 방법으로 새롭게 제안되고 있다.1 운동피질 흥분성에 대한 연구에 따르면 양극성 경두개 직류자극은 신경의 탈분극을 유발하 는 반면 음극성 경두개 직류자극은 과분극을 발생시켜 흥분성 억제 효과를 유발할 수 있음을 보여준다. ${ }^{13}$ 경두개 직류자극은 안전하며 다른 비침습적인 뇌 자극 장비에 비해 경제적이라서 연구 또는 임상 적 중재를 목적으로 이용되고 있고 ${ }^{14}$ 적용 질환의 폭도 넓다. 특히 뇌 졸중 만성 통증, 근긴장 이상증을 포함한 근뼈대계에 효과적으로 이 
용되고 있고 ${ }^{15}$ 시각운동성 조절, ${ }^{16}$ 알츠하이머 병을 가진 쥐를 이용하 여 경두개 직류자극 효과를 확인한 연구, ${ }^{17}$ 다발성 경화증 환자 치료 를 위한 연구18 등이 신경계에도 적용되고 있으며 정신과적인 증상인 외상 후 스트레스 장애에도 이용되고 있다..$^{19}$ 또한 일반인을 넘어 축 구 선수의 균형능력에 대한 경두개 직류자극 영향을 확인한 연구 20 등이 보고되고 있다. 경두개 직류자극을 이용한 많은 연구들에서 자 극을 받는 동안이나 자극 후 나타나는 다양한 운동 기능의 촉진을 제시하고 있으며, ${ }^{21}$ 경두개 직류자극을 적용 후 근육 기능을 개선함 으로써 근육의 지구력을 향상시킨다고 하였다.22

이처럼 경두개 직류자극의 긍정적인 효과에 대하여 잘 알려져 있 지만 본 연구에서 확인하고자 하는 허리 통증이 있는 자를 대상으로 경두개 직류자극을 적용 후 정규화된 자세균형 측정시스템인 space balance $3 \mathrm{D}$ 를 이용하여 균형에 대한 연구는 아직 부족한 실정이다. 그 러므로 본 연구에서는 경두개 직류자극을 적용 후 균형 측정 시스템 을 이용하여 만성 허리 통증이 있는 자의 균형 능력에 미치는 영향을 확인하고자 한다.

\section{연구 방법}

\section{1. 연구대상}

본 연구는 허리 통증으로 병원에서 허리 통증 진단을 받고 허리 통증 이 있는 대상으로 VAS 2-3점에 해당되는 자로 선정하였다. 대상자는 20 대 총 남녀 30 명을 대상으로 대상자에게 군에 대한 정보를 알리지 않고 단일맹검법(single-blind test)으로 단순무작위추출방법을 사용 하여 경두개 직류자극을 거짓으로 적용군(sham transcranial direct current stimulation group, STDCSG) 15명, 경두개 직류자극을 지속적 적용군(continuous transcranial direct current stimulation group CTDCSG) 15 명으로 분류하여 실험을 하였다. 실험 전 연구에 대한 목적 및 운동 방법 등을 설명하고 자발적인 연구 참여를 희망하고 연구 동 의서를 작성한 자로 선정하여 연구를 시행하였고 실험 전 대상자의 동질성 검정 결과 연령, 신장, 체중에서 유의한 차이가 없어 동일한 집 단임을 확인하였고 일반적 특성은 Table 1과같다.

Table 1. General characteristics of subjects

\begin{tabular}{lccc}
\hline & STDCSG $(n=15)$ & CTDCSG $(n=15)$ & $p$ \\
\hline Age $(\mathrm{yr})$ & $21.3 \pm 2.21$ & $21.3 \pm 1.49$ & 1.000 \\
Height $(\mathrm{cm})$ & $167.9 \pm 9.51$ & $169.4 \pm 9.63$ & 0.730 \\
Weight $(\mathrm{kg})$ & $64.0 \pm 10.45$ & $69.2 \pm 13.21$ & 0.344 \\
\hline
\end{tabular}

Mean \pm SD.

STDCSG: sham transcranial direct current stimulation group, CTDCSG: continuous transcranial direct current stimulation group.

\section{2. 실험방법}

\section{1) 연구 절차}

경두개 직류자극 적용은 대상자가 편안하게 앉은 자세에서 직류자 극기(Endomed 581, Enraf Nonius Co., The Netherlands)를 사용하여 자 극을 주었다. 전극은 $7 \times 5 \mathrm{~cm}$ 크기의 스펀지 전극을 사용하였으며 흔 들림을 방지하기 위해 밴드를 이용하여 고정하였다. 두 군 모두 양극 전극은 international 10-20 system에 따라 코와 귀에서 이은 점이 만나 는 마루엽의 $\mathrm{CZ}$ 에 배치하고, 음극 전극은 왼쪽 눈확 위쪽에 배치하였 다. ${ }^{23}$ 자극 시 강도는 $2 \mathrm{~mA}{ }^{24}$ 적용 시간은 의자에 앉아서 10 분 자극하 였고 주 3 회총 4 주 적용하였다.

\section{2) 측정도구 및 방법}

자세 균형 능력 측정에 사용된 자세균형 측정시스템(Space balance 3D, Cyber Medic Co., Korea)은 두 개의 무선 지면 반발력 장치(wireless force plate)가 내장되어 4 정점(좌측 우측 발가락, 뒤꿈치)의 체중 분포 도를 확인할 수 있으며, 기기의 전방에 위치한 센서는 몸통 기울기를 측정할 수 있다. 기기를 이용한 평가 시 실험자가 수행하는 움직임은 발판을 통한 발바닥의 압력과 센서를 통한 각도가 실시간으로 컴퓨 터로 전송되어 컴퓨터 모니터 화면에 표시된다. 평가 시 대상자들은 기기장치 위로 올라가 발판에 발이 움직이지 않게 고정한 후 대상자 용 모니터를 응시한 채 가슴 앞에 X자로 팔을 놓고 검사를 시작한다. 균형 평가는 눈을 뜬 상태와, 눈을 감은 상태 2 가지로 구성되어 있고 눈을 뜬 상태와 눈을 감은 상태에서 균형 능력을 평가하였다. 그리고 두 가지 균형검사는 각각 20 초씩 소요되며 자세균형 측정시스템 모 니터에 표시된 balance posture ratio (BPR) 점수는 A-E 구역(zone)의 비 율(ratio)에 가중치 $(\mathrm{A}=100 \%, \mathrm{~B}=80 \%, \mathrm{C}=60 \%, \mathrm{D}=40 \%, \mathrm{E}=20 \%)$ 를 곱 해서 점수를 계산하고 최대 점수는 100 점, 최저 점수는 20 점이다. ${ }^{25}$ 실 험 전 측정은 본 실험 1 주 전에 측정하였고 각 3 회 측정 후 평균값을 이용하였다.

\section{3. 분석방법}

본 연구의 결과 분석은 SPSS for Window ver 18.0 통계 프로그램을 이용 하여 평균과 표준편차를 산출하였다. 그룹 내 실험 전후 비교를 위하 여 대응 t-검정(paired t-test)을 사용하였고, 그룹 간 비교와 실험 전과 후의 평균 값을 비교하기 위해 독립 t-검정(independent t-test)을 사용하 였다. 통계학적 유의성을 검증하기 위해 유의수준은 $\alpha=0.05$ 로 하였다.

\section{결 과}

\section{1. 눈을 뜬 상태에서 측정된 그룹 내, 그룹 간 정적 균형 변화}

눈을 뜬 상태에서 측정된 정적 균형 변화는 STDCSG는 경두개 직류 
Table 2. Comparison of open eye static balance

(score)

\begin{tabular}{lcccc}
\hline & Pre & Post & Post-Pre & $\mathrm{p}$ \\
\hline STDCSG & $84.7 \pm 14.22$ & $86.3 \pm 12.96$ & $1.7 \pm 4.18$ & 0.14 \\
CTDCSG & $75.6 \pm 18.91$ & $85.7 \pm 15.49$ & $10.1 \pm 12.84$ & $0.01^{*}$ \\
$\mathrm{p}$ & 0.15 & 0.9 & $0.02^{*}$ & \\
\hline
\end{tabular}

Mean \pm SD

STDCSG: sham transcranial direct current stimulation group, CTDCSG: continuous transcranial direct current stimulation group. ${ }^{*} \mathrm{p}<0.05$.

Table 3. Comparison of close eye static balance

(score)

\begin{tabular}{lcclc}
\hline & Pre & Post & Post-Pre & $p$ \\
\hline STDCSG & $63.6 \pm 13.98$ & $64.8 \pm 16.17$ & $1.2 \pm 6.76$ & 0.49 \\
CTDCSG & $59.8 \pm 15.27$ & $65.3 \pm 16.40$ & $5.5 \pm 12.55$ & 0.11 \\
$p$ & 0.49 & 0.94 & 0.26 & \\
\hline
\end{tabular}

Mean \pm SD.

STDCSG: sham transcranial direct current stimulation group, CTDCSG: continuous transcranial direct current stimulation group.

자극 적용 전 $(\mathrm{M}=84.7)$ 과 적용 후 $(\mathrm{M}=86.3)$ 에 통계적으로 유의한 차 이가 없었고 $(\mathrm{p}>0.05), \mathrm{CTDCSG}$ 는 경두개 직류자극 적용 전(M=75.6) 보다 적용 후 $(\mathrm{M}=85.7)$ 에 통계적으로 유의한 차이가 있었다 $(\mathrm{p}<0.05)$. 그룹 간 비교에서 경두개 직류자극 적용 후 STDCSG $(\mathrm{M}=86.3)$ 와 CTDCSG $(\mathrm{M}=85.7)$ 는 통계적으로 유의한 차이가 없었고 $(\mathrm{p}>0.05)$, 경 두개 직류자극 적용 전과 적용 후의 평균 차이에서는 STDCSG $(\mathrm{M}=1.7)$ 보다 CTDCSG $(\mathrm{M}=10.1)$ 가 통계적으로 유의한 차이가 있었 다 $(\mathrm{p}<0.05)$ (Table 2$)$.

\section{2. 눈을 감고 측정된 그룹 내, 그룹 간 정적 균형 변화}

눈을 감은 상태에서 측정된 정적 균형 변화는 STDCSG는 경두개 직류 자극 적용 전(M=63.6)과 적용 후 $(\mathrm{M}=64.8)$ 에 통계적으로 유의한 차이 가 없었고( $\mathrm{p}>0.05), \mathrm{CTDCSG}$ 는 경두개 직류자극 적용 전(M=59.8)과 적용 후 $(\mathrm{M}=65.3)$ 에 통계적으로 유의한 차이가 없었다 $(\mathrm{p}>0.05)$. 그룹 간 비교에서 경두개 직류자극 적용 후 STDCSG $(\mathrm{M}=64.8)$ 와 CTDCSG $(\mathrm{M}=65.3)$ 는 통계적으로 유의한 차이가 없었고 $(\mathrm{p}>0.05)$, 경두개 직류 자극 적용 전과 적용 후의 평균 차이에서는 STDCSG $(\mathrm{M}=1.2)$ 와 CTDCSG $(\mathrm{M}=5.5)$ 는 통계적으로 유의한 차이가 없었다( $\mathrm{p}>0.05)$ (Table 3).

\section{고 찰}

본 연구는 허리 통증이 있는 자를 대상으로 경두개 직류전류 적용이 정적 균형에 미치는 영향을 확인하고자 수행되었다. 균형 측정 장비 로 이용된 자세균형 측정시스템은 다양한 운동과 정확한 시간을 설 정할 수 있다는 장점으로 부상에 있어 안전하며 몸통 안정화 운동을 시행하는 사람에게 적합한 운동 장치이며 ${ }^{26}$ 균형 평가도구로 자주 이 용되고 있는 장비이다.
그 결과 눈을 뜬 상태에서 균형 변화는 CTDCSG에서 시기별 변화 에서 유의한 차이가 있었고, 그룹 간 비교에서 경두개 직류자극 적용 후와 적용 전 평균차이에서 유의한 차이가 있었다. 눈을 감은 상태에 서 균형 변화는 시기별과 그룹 간 변화에서 유의한 차이가 없었다.

Yang 등 ${ }^{20}$ 은 대학 축구 선수 30 명을 대상으로 8 주 동안 매주 50 회 씩 일주일에 5 회 경두개 직류자극 자극을 수행하여 넙다리곧은근의 근 활성도와 균형능력이 증가하였다고 보고하였고, $\operatorname{Park}^{27}$ 은 축구선 수 15 명을 대상으로 감각운동훈련과 병행한 경두개 직류자극 자극 을 주 7 회 20 분간 적용하여 균형 능력을 평가하였는데 감각운동훈련 과 경두개 직류자극 자극을 이용한 그룹에서 유의한 차이가 발생하 였다고 보고하였다. 또한 Lattari 등 28 은 40 세에서 90 세 사이의 파킨슨 환자의 17 명을 대상으로 뒤가쪽 이마엽 겉질 부위에 경두개 직류자 극 자극을 적용한 결과 균형과 보행이 개선되었다 보고하였고, Kaminkki 등 29 은 젊은 26 명의 대상을 이용하여 일차운동피질의 다리 영 역에 해당되는 부위에 적용한 결과 동적 균형 능력 및 보행을 향상시 킨다고 보고하였다. 경두개 직류자극에 대한 정확한 프로토콜이 없 기 때문에 해석하기에는 다소 무리가 있지만 일반적으로 10 분에서 20 분간 경두개 직류자극을 받을 때 30 분에서 1 시간 동안 효과가 지 속되고 1 주일 반복 자극을 받으면 1 주일에서 2 주일 동안 효과가 지속 되는 것으로 알려져 있다. ${ }^{30}$ 또한 경두개 직류자극은 자극강도와 지 속시간 자극 위치에 따른 다양한 변화가 발생한다. ${ }^{31}$ 경두개 직류자 극은 일차 운동감각영역 및 전 운동영역부위의 손 기능을 증진시키 고 작업기억능력을 촉진하며 뒤통수엽 부위의 자극은 시지각 운동 능력을 향상시킨다고 하였다. ${ }^{22}$ 일차 운동영역에 해당되는 $\mathrm{CZ}$ 부위에 경두개 직류자극 양극 전극 자극은 균형 능력과 보행 능력을 향상시 킨다고 알려져 있다. ${ }^{33}$

이러한 효과들로 인해 $\mathrm{CZ}$ 부위에 경두개 직류자극이 허리 통증을 가지고 있는 자의 정적균형 능력에 미치는 영향을 알아보고자 본 연 구를 설계하였다. 하지만 선행연구들의 결과는 본 연구와 다소 차이 가 있었다. 이러한 결과는 선행연구의 전극적용 부위와 경두개 직류 자극 적용 기간, 경두개 직류자극 적용 시간의 차이로 인한 결과로 생 각된다. 선행연구는 8 주 동안 주 5 회씩 경두개 직류자극 자극을 $\mathrm{CZ}$, $\mathrm{C} 3, \mathrm{C} 4$ 위치에 양극 전극을 적용하여 수행하였고, 또 다른 연구는 일 차 체성감각피질 부위인 $\mathrm{S} 1$ 부위에 부착하여 $1 \mathrm{~mA}$ 를 이용하여 20 분 간 적용하여 본 연구의 적용 방법과 적용 시간의 차이가 있었다. CZ 부위에 양극 전극을 부착한 선행연구 또한음극과 양극 차이를 본 연 구로 본 연구의 적용 방법과 다소 차이가 있었다. 본 연구는 4 주간 주 3 회씩 10 분간 $\mathrm{CZ}$ 위치에만 양극 전극을 적용하여 적용 위치와 자극 빈도가 상대적으로 낮아 눈 뜬 상태에서의 균형 능력 변화만 발생하 였고 눈 감고 측정한 균형능력은 차이가 없었던 것으로 생각된다. Madhavan 등 34 은 경두개 직류자극을 일차 운동피질 영역인 M1에 적 
용하여 다리의 근육의 흥분성을 증가시킨다고 하여 시각을 차단했 을 때 균형에 영향을 미치는 다리 근육의 흥분성을 증가시키기에 본 연구에서 CZ에만 적용된 자극이 부족하지 않았나 생각이 든다. 하지 만 증가 비율을 보면 자극 전극 부착 부위를 확대하여 오랜 기간 동 안 적용하였다면 눈 감은 상태에서 균형에 대한 변화도 발생할 가능 성이 높다고 생각되며, 젊은 사람을 대상으로 한 연구에 따르면 특정 한계 내에서 자극 강도 및 지속 시간이 증가하면 경두개 직류자극의 효능이 증가되는 것으로 나타나 ${ }^{35}$ 본 연구에서 적용한 방법으로 인해 이러한 결과가 발생한 것으로 생각된다.

결론적으로 경두개 직류자극은 허리 통증이 있는 자의 균형 능력 에 미흡하지만 긍정적으로 적용된다는 점을 확인할 수가 있었다. 본 연구는 표본집단의 크기가 작았고 20대 요통 환자만을 대상으로 하 여 급성과 만성 질환 환자나 노인과 같은 특수성을 가진 집단에는 일 반화하기에는 어렵다. 하지만 실험을 통해 발생한 변화량은 긍정적 으로 생각되며 향후 연구에서는 근뼈대계 질환과 신경계 질환, 특수 성을 가진 대상자들로 심도 있는 연구가 필요해 보이며 본 연구에서 확인하지 못한 균형과 관련된 근육의 특성에 대한 연구가 필요해 보 인다. 결론으로 경두개 직류자극을 이용한 중재 방법은 요통 환자의 균형 능력에 긍정적으로 작용되어 임상에서 요통 환자의 중재로서 활용 가치와 기초 자료로 활용 가능성을 기대해 본다.

\section{REFERENCES}

1. Buchbinder R, van Tulder M, Öberg B et al. Low back pain: A call for action. The Lancet. 2018;391(10137):2384-8.

2. Hurwitz EL, Randhawa K, Yu H et al. The global spine care initiative: A summary of the global burden of low back and neck pain studies. Eur Spine J. 2018;27(6):796-801.

3. Dunn KM, Hestbaek L, Cassidy JD. Low back pain across the life course. Best Pract Clin Rheumatoi. 2013;27(5):591-600.

4. Imamura M, Imamura ST, Targino RA et al. Paraspinous lidocaine injection for chronic nonspecific low back pain: A randomized controlled clinical trial. J Pain. 2016;17(5):569-76.

5. Chung SG. Rehabilitative treatments of chronic low back pain. Journal of the Korean Medical Association. 2007;50(6):494-506.

6. Jacobs JV, Lyman CA, Hitt JR et al. Task-related and person-related variables influence the effect of low back pain on anticipatory postural adjustments. Hum Mov Sci. 2017;54:210-9.

7. Tsao H, Galea M, Hodges P. Reorganization of the motor cortex is associated with postural control deficits in recurrent low back pain. Brain. 2008;131(8):2161-71.

8. Jacobs JV, Lomond KV, Hitt JR et al. Effects of low back pain and of stabilization or movement-system-impairment treatments on induced postural responses: A planned secondary analysis of a randomised controlled trial. Man Ther. 2016;21:210-9.

9. Kim J, Lee C, Suk K. Prevalence of neuropathic pain and patient-reported outcomes in korean adults with chronic low back pain. J Korean Soc
Spine Surg. 2016;23(23):S8-10.

10. Chou R, Côté P, Randhawa K et al. The global spine care initiative: Applying evidence-based guidelines on the non-invasive management of back and neck pain to low-and middle-income communities. Eur Spine J. 2018;27(6):851-60.

11. Nitsche MA, Paulus W. Transcranial direct current stimulation-update 2011. Restor Neurol Neurosci. 2011;29(6):463-92.

12. Utz KS, Dimova V, Oppenländer K et al. Electrified minds: Transcranial direct current stimulation (tdcs) and galvanic vestibular stimulation (gvs) as methods of non-invasive brain stimulation in neuropsychologya review of current data and future implications. Neuropsychologia. 2010;48(10):2789-810.

13. Kropotov JD. Functional neuromarkers for psychiatry: Applications for diagnosis and treatment. Cambridge, Academic Press, 2016.

14. Schlaug G, Renga V. Transcranial direct current stimulation: A noninvasive tool to facilitate stroke recovery. Expert Rev Med Devices. 2008; 5(6):759-68.

15. Lefaucheur JP, Antal A, Ayache SS et al. Evidence-based guidelines on the therapeutic use of transcranial direct current stimulation (tdcs). Clin Neurophysiol. 2017;128(1):56-92.

16. Kwon YH, Cho JS. Effect of transcranial direct current stimulation on visuomotor coordination task in healthy subjects. J Kor phys Ther. 2014;26(6):386-90.

17. Kim JY, Park SD, Song HS et al. The effect of transcranial direct current stimulation on cognitive function and biochemical change of rats with alzheimers desease. J Kor phys Ther. 2014;26(6):436-41.

18. Workman C, Kamholz J, Rudroff T. Transcranial direct current stimulation (tdcs) for the treatment of a multiple sclerosis symptom cluster. Brain Stimul. 2019; Available online 25.

19. Ahmadizadeh MJ, Rezaei M, Fitzgerald PB. Transcranial direct current stimulation (tdcs) for post-traumatic stress disorder (ptsd): A randomized, double-blinded, controlled trial. Brain Res Bull. 2019.

20. Yang DJ, Park SK, Uhm YH. Influence of transcranial direct current stimulation on lower limb muscle activation and balance ability in soccer player. J Kor Phys Ther. 2018;30(6):211-7.

21. Kwon YH, Cho JS. Effect of transcranial direct current stimulation on movement variability in repetitive-simple tapping task. J Kor Phys Ther. 2015;27(1):38-42.

22. Cogiamanian F, Marceglia S, Ardolino G et al. Improved isometric force endurance after transcranial direct current stimulation over the human motor cortical areas. Eur J Neurosci. 2007;26(1):242-9.

23. Nitsche MA, Cohen LG, Wassermann EM et al. Transcranial direct current stimulation: State of the art 2008. Brain Stimul. 2008;1(3):206-23.

24. Jeffery DT, Norton JA, Roy FD et al. Effects of transcranial direct current stimulation on the excitability of the leg motor cortex. Exp Brain Res. 2007;182(2):281-7.

25. Choi JM, Lee JH, Ha HG et al. Reliability and concurrent validity of the balance evaluation using space balance $3 \mathrm{~d}$ and tinetti mobility test in subacute stroke patients. The Journal of the Korea Contents Association. 2012;12(8):264-73.

26. Yu JY, Park JC, Jeong JG. Influence of multi-directional dynamic stabilization exercise on thickness of abdominal muscles. J Kor Phys Ther. 2016;28(4):249-53.

27. Park WS. The effect of sensory motor training and transcranial direct 
current stimulation to improvement of balance ability for soccer player. Dong Shin University. Dissertation of Master's Degree. 2018.

28. Lattari E, Costa SS, Campos C et al. Can transcranial direct current stimulation on the dorsolateral prefrontal cortex improves balance and functional mobility in Parkinson's disease? Neurosci Lett. 2017;636:1659.

29. Kaminski E, Steele CJ, Hoff M et al. Transcranial direct current stimulation (tdcs) over primary motor cortex leg area promotes dynamic balance task performance. Clin Neurophysiol. 2016;127(6):2455-62.

30. Butts RJ, Kolar MB, Newman-Norlund RD. Enhanced motor skill acquisition in the non-dominant upper extremity using intermittent theta burst stimulation and transcranial direct current stimulation. Front Hum Neurosci. 2014;8:451.

31. Boggio PS, Bermpohl F, Vergara AO et al. Go-no-go task performance improvement after anodal transcranial dc stimulation of the left dorso- lateral prefrontal cortex in major depression. J Affec Disord. 2007;101(13):91-8.

32. Antal A, Nitsche MA, Kruse W et al. Direct current stimulation over v5 enhances visuomotor coordination by improving motion perception in humans. J Cogn Neurosci. 2004;16(4):521-7.

33. Kim HJ. The effects of transcranial direct current stimulation polarity on brain activity, balance and gait in hemiplegic patient. Seonam University. Dissertation of Doctorate Degree. 2014.

34. Madhavan S, Rogers LM, Stinear JW. A paradox:afterstroke,the non-lesioned lowerlimb motorcortex may bemaladaptive. Eur J Neurosci. 2010;32(6):1032-9.

35. Nitsche MA, Paulus W. Sustained excitability elevations induced by transcranial dc motor cortex stimulation in humans. Neurology. 2001; 57(10):1899-901. 